\title{
La sainte boue
}

Patrick Autréaux

\section{(2) OpenEdition}

Journals

Édition électronique

URL : http://journals.openedition.org/ccs/1881

DOI : $10.4000 /$ ccs. 1881

ISSN : 2558-782X

\section{Éditeur :}

Presses universitaires de Rennes, Association des lecteurs de Claude Simon

\section{Édition imprimée}

Date de publication : 30 août 2018

Pagination : 229-231

ISBN : $978-2-7535-7489-2$

ISSN : 1774-9425

\section{Référence électronique}

Patrick Autréaux, "La sainte boue », Cahiers Claude Simon [En ligne], 13 | 2018, mis en ligne le 30 août 2019, consulté le 19 février 2020. URL : http://journals.openedition.org/ccs/1881 ; DOI : 10.4000/ccs 1881 


\title{
LA SAINTE BOUE
}

\author{
Patrick AUTRÉAUX ${ }^{1}$
}

L'enchaînement est presque toujours identique: l'empreinte du plaisir à lire Claude Simon s'est insinuée dans le fil des jours, je prends un de ses livres dans la bibliothèque, lis quelques lignes, le repose non loin de moi sur le bureau ou la table de chevet. Je me réjouis de le relire bientôt, mais d'autres livres s'interposent, deux ou trois que je dois avoir terminés pour mériter le plaisir qui attend. Et puis d'autres encore. Le nom de Claude Simon n'est pas recouvert ou s'il l'est je le déterre, je guette le moment où rien ne s'imposera, aucune autre envie; alors, plein d'un désir pur, je plongerai.

Convoiter le trésor d'un livre, avoir la certitude qu'il existe bien et que ce n'est pas un mirage ou un ouï-dire. Avoir déjà fait l'expérience d'une écriture et savoir qu’on ne peut être déçu. Savoir et désirer mais retarder sans cesse. Jouer avec ce retard, et avec le livre comme avec un fruit qu'on hume mais qu'on ne mange pas. Jouer jusqu'au moment où on le mord. Lire dix, trente, soixante pages. Et dès les premières lignes et pages tout retrouver, les mêmes avidité, fascination, contentement qui mènent presque à l'écœurement. On avait fait grandir sa faim et on est rassasié. On ferme le livre, on le repose sur la pile, il y restera encore longtemps, jusqu'à ce que le désir se soit estompé, on pourra le reprendre, se renfoncer dans sa matière. Et puis ce sera fini, pour quelque temps du moins, le livre rejoindra le trou dans les rayonnages.

Peu d'auteurs donnent cette sensation.

Il y a ceux qui dynamitent notre manière de lire, qui nous rendent infirmes à lire d'autres qu'eux-mêmes, Céline, et, pour fascinants qu'ils puissent être, font

1. Patrick Autréaux est écrivain. Dernier ouvrage paru: La Voix écrite (Verdier, 2017). À noter également la réédition de deux textes plus anciens: Dans la vallée des larmes suivi de Soigner (Gallimard, «Folio », 2017). 
perdre le goût de la multiplicité, ferment l'horizon. Il y a ceux qui captent et retiennent sans stratagème dans les méandres de leur labyrinthe, Proust ou son mentor Saint-Simon. Il y a ceux qui ouvrent l'espace psychique sur ses propres arcanes, Michaux ou Bataille. Vous revenez à eux pour que l'imaginaire se décloisonne et désentrave vos doigts et les mots qui en coulent. Car ce sont les doigts qui écrivent, eux qui font sourdre le grattement du papier ou les claquements sériels du clavier, qui hypnotisent le regard et vous font baisser la tête vers la table, vous immobilisent dans un fouissement fixe, vous absentent. Il y a ceux qu'on a aimé lire et qu'on relit mais qui sont des possibles qui vous éloignent de vous-mêmes ou du moins n'ouvrent pas une de ces cavernes étranges et familières où se produisent les vraies rencontres. Ainsi de Gracq, Calaferte, Giono, Sarraute, Camus ou de certains anciens dont la rationalité vous satisfait mais qui ne creusent pas là où vous sentez devoir aller. Il y a pourtant Hugo, poète, qui sait, comme Michaux ou Dickinson, ouvrir cet espace - rendre à l'aventure. Il y a aussi certains - ainsi de Duras - en qui on aimerait avoir confiance mais qui vous déçoivent inexplicablement. On les lit, heureux de les lire, d'essayer encore, et brusquement on se sent happé par un silence qui vous fait reculer: on manque d'un organe pour les vivre.

Et puis il y a ceux qui lèvent le désir de matière, de s'y enfouir, de nager ou de rouler dans le sol, dans la boue, dans l'herbe, d'entrer dans le tronc des arbres ou dans les murs même, leur corps. De redevenir matière mais désormais consciente et de goûter la joie intense d'être matière individuée dans la matière en chaos, de flotter sur les courants de sa décomposition. Les plasticiens donnent plus volontiers que les écrivains cette sensation, quand on regarde de très près et très longtemps, quand on s'approche des pigments et du grain de chaque trait, quand on renifle le papier ou la toile et que l'aquarelle brouille vos yeux de pleurs, que l'huile appelle vos mains et que vous voulez pénétrer dans cette huître de la peinture qui semble offrir le goût salé des muqueuses.

Claude Simon vous projette à terre, le visage et la bouche, le nez contre le sol, contre des murs, contre des roches ou l'eau mais sans vous humilier, il ne tente d'ailleurs pas de vous pousser de l'autre côté de quelque miroir mais vous fait sentir qu'il n'est pas d'autre côté, seulement un endroit infini, l'interminable visible d'un ruban à unique surface, la sensation que l'invisible n'est qu'un visible inaperçu.

C'est en raison de la satiété qu'il procure que j'interromps chaque fois ma lecture de Simon, et pas à cause de l'ennui ou de l'hermétisme. Même si dans la plénitude point un tout petit manque, comme lorsqu'on regarde certaines instal- 
lations de filaments et de bulles, ou les anémones et mollusques des fonds marins, comme lorsqu'on pénètre de caresses les nappages et linéaments d'une peinture sur papier: un manque qui bée de ne pouvoir s'y fondre - mais qui fait écrire.

Claude Simon aura été pour moi la dernière étape du lecteur devenant écrivain. Peut-être parce qu'il me permit de rompre avec un très ancien interdit.

J'avais gardé du lycée la marque infamante de ces corrections faites au rouge sur mes copies en raison de mon usage intempestif du participe présent, par imitation des gérondifs latins sans doute. On m'avait répété que ma phrase traînait et se languissait, qu' elle perdait en vie à cause de ce temps, de ces répétitives sonorités assonantes. Pourtant j'aimais patauger dans ces «ssant " et " nant » et " rant » et " pant " et " dant » et " mant " et «tant "; j'aimais cette lente coulée de verbes alanguis comme des limaces et dont les vocalises étaient une bave ponctuée de virgules. Mes doigts s'en délectaient. Je les scandais, c'était un solfège qui épousait des images enfouies en moi. Je voyais et sentais en même temps le rythme de ces phrases, elles semblaient l'eau d'un ruisseau qui coulait lentement, charriant toute une matière organique et la terre, creusant et découvrant par endroit des galeries dans les rives miniatures des ruisseaux où j'avais aimé patauger. Le participe présent était cela.

Et puis je découvris La Route des Flandres. Simon lui n'était pas bridé par cet interdit, il l'avait domestiqué et en avait fait un livre de boue. L'interdit scolaire venait de tomber. Je retrouvais les vocalises et le ronron alangui des phrases chargées de participes.

Il faut avoir la liberté des outils pour écrire. Et être passé par la boue du monde, en avoir senti l'horreur et goûté le plaisir pour trouver l'équilibre de sa voix.

Boue du présent où l'on patauge, matière dont on ne distingue pas la forme, réel informe. Matière psychique de la mémoire, matière du temps vivant. La boue n'est-elle pas condition de la vie en son origine? Quand tout se déforme et reforme, nous absorbe. Quand on ne cherche plus rien mais qu'on continue à fouiller.

Ce sont les strates de cette boue déposée en moi que remuait le courant Simon. À sa suite, il m'enfonçait non vers les très grands fonds mais dans les villosités de ce que pourrait être la "prose du monde». 